\title{
Oncocytic carcinoma of the salivary gland with thymoma: A case report and review of the literature
}

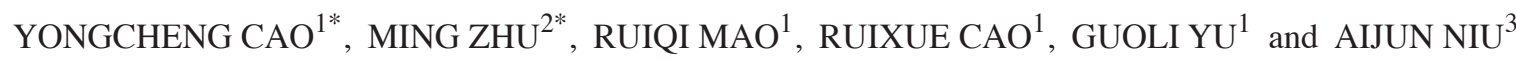 \\ Departments of ${ }^{1}$ Pathology, ${ }^{2}$ Radiology and ${ }^{3}$ Laboratory Medicine, \\ General Hospital of Jinan Military Command, Jinan, Shandong 250031, P.R. China
}

Received March 22, 2014; Accepted October 15, 2014

DOI: $10.3892 / \mathrm{ol} .2014 .2707$

\begin{abstract}
Oncocytic carcinoma (OC) arising in the salivary gland is a very rare tumor with only 32 previously reported cases. In this report, we describe a novel case of oncocytic carcinoma with associated thymoma, which arose in the left parotid gland of a 66-year-old male with a history of a painless left parotid mass for 1 year. Oncocytes are large, polygonal cells that are characterized by marked cellular atypia, frequent mitoses, wide eosinophilic granular cytoplasm, a central nucleus and a prominent nucleolus. The follow-up data showed no evidence of recurrence and the patient is in a good health 20 months after the surgery. In the current case, the patient had not only OC but also thymoma, which is exceedingly rare and may represent the first documented case in the literature.
\end{abstract}

\section{Introduction}

Oncocytic carcinomas (OCs) are very rare neoplasms that have been reported to occur in the nasal and thoracic cavities, ovary, kidney, thyroid gland, salivary gland, breast and parathyroid $(1,2)$. These tumors represent $11 \%$ of all oncocytic salivary gland neoplasms, $0.5 \%$ of all epithelial salivary gland malignancies and $0.18 \%$ of all epithelial salivary gland tumors (1). Bauer and Bauer (3) reported the first case in 1953, and, in total, only 31 cases have been reported in English-language literature (4-22).

Oncocytes are typically large epithelial cells with a low nuclear-to-cytoplasmic ratio, a centrally situated round nucleus with a prominent nucleolus and an abundant bright eosinophilic granular cytoplasm that is ultrastructurally characterized by numerous mitochondria (14). Thymic epithelial tumors include thymomas and thymic carcinomas. Although occurence is rare (accounting for $0.2-1.5 \%$ of all

Correspondence to: Dr Aijun Niu, Department of Laboratory Medicine, General Hospital of Jinan Military Command, 25 Shifan Road, Jinan, Shandong 250031, P.R. China

E-mail: niuaijun4597@163.com

*Contributed equally

Key words: oncocytic carcinoma, salivary, thymoma, PTAH stain malignancies) (23), they present the most common tumor of the anterior mediastinum (24). Thymomas are neoplasms arising from or exhibiting differentiation towards thymic epithelial cells. Thymomas are classified into two major types depending on whether the neoplastic epithelial cells have an oval shape and are uniformly bland (type A thymoma) or whether the cells have a predominantly round or polygonal appearance (type B thymoma). Thymomas which exhibit type A and B-like features are classified as type AB (25). In this case report, the patient not only had OC but also thymoma. To the best of our knowledge, this is the first reported case of an OC patient exhibiting type AB thyoma. Written informed consent was obtained from the patient.

\section{Case report}

Case presentation. A 66-year-old male was admitted to the General Hospital of Jinan Military Command (Jinan, China) with a 1-year history of a painless left parotid mass that was gradually increasing in size. Physical examination revealed a fixed, hard, $3 \times 2-\mathrm{cm}$ mass with a smooth surface in the left parotid region. There was no palpable lymph node in the parotid gland or on the left side of the neck. Systemic physical and laboratory examinations revealed no abnormalities. Echography of the neck revealed an area of mixed echoes in the left parotid gland. Computed tomography (CT) demonstrated a 3x2-cm solid lesion in the left parotid gland and a $4.5 \times 4.5-\mathrm{cm}$ mass in the region of thymus. Radical resection of the parotid tumor and thoracotomy resection of the thymic tumor were performed.

Tissue staining. The specimen was fixed in neutral buffered formalin and routinely processed with tissue sections embedded in paraffin. The sections were cut into $4-\mu \mathrm{m}$ slices and stained with hematoxylin and eosin (H\&E) for conventional evaluation. In addition to $\mathrm{H} \& \mathrm{E}$, the following immunostains and special tissue stains were used: Cytokeratin (CK, AE1/AE3; Dako, Carpinteria, CA, USA), carcinoembryonic antigen (CEA; Zymed, San Francisco, CA, USA), p53 (Dako), S-100 (4c4.9; Zymed), Ki-67 (Dako) and phosphotungstic acid-hematoxylin (PTAH; Shanghai Lanji Science and Technology Co., Ltd., Shanghai, China).

Macroscopic findings. The parotid tumor consisted of unencapsulated, irregular, cord-like, tan to gray masses. The cut 


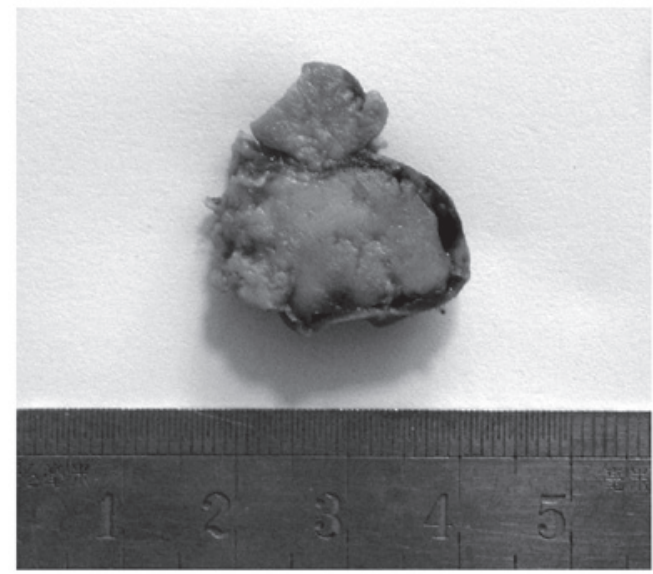

Figure 1. The cut surface of the parotid tumor, which was solid.

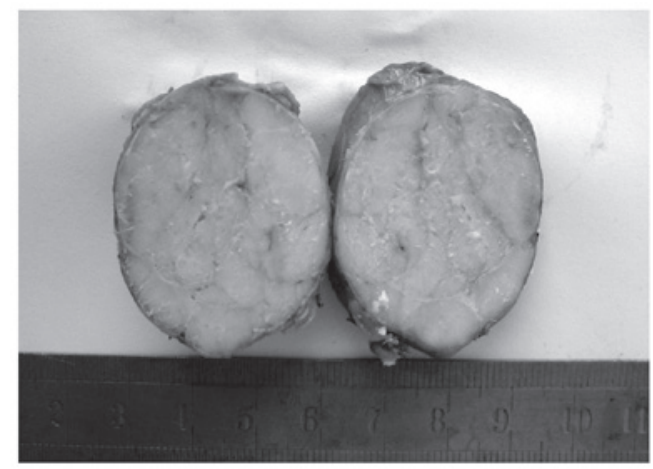

Figure 2. The tumor of the thymus was encapsulated and its cut surface was and solid.

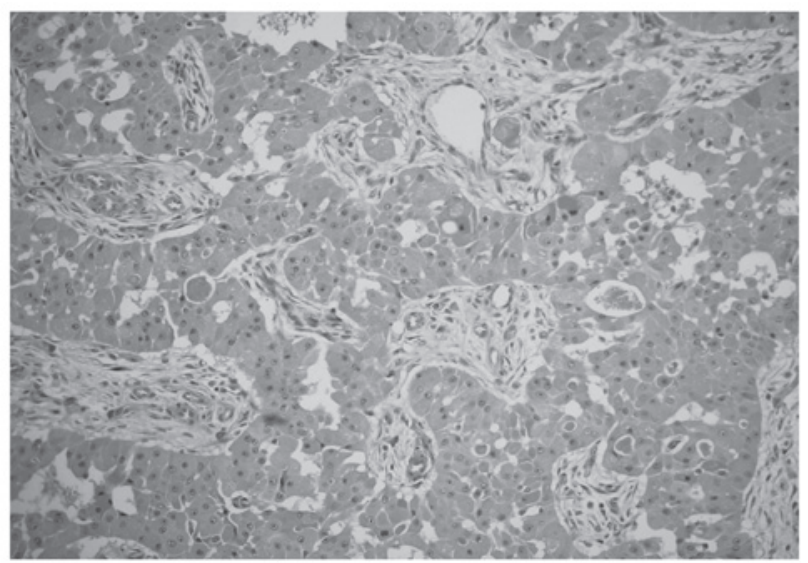

Figure 3. Oncocytic carcinoma of the parotid gland (stain, hematoxylin and eosin; magnification, $\mathrm{x} 200$ ).

surface was light brown, solid, and non-homogeneous with cystic degeneration, necrosis or hemorrhage (Fig. 1). The tumor of the thymus was encapsulated and its cut surface was solid and light brown (Fig. 2).

Microscopic findings and immunohistochemistry. The parotid tumor had replaced a large area of the parotid gland, but perineural invasion and vascular invasion were not found.

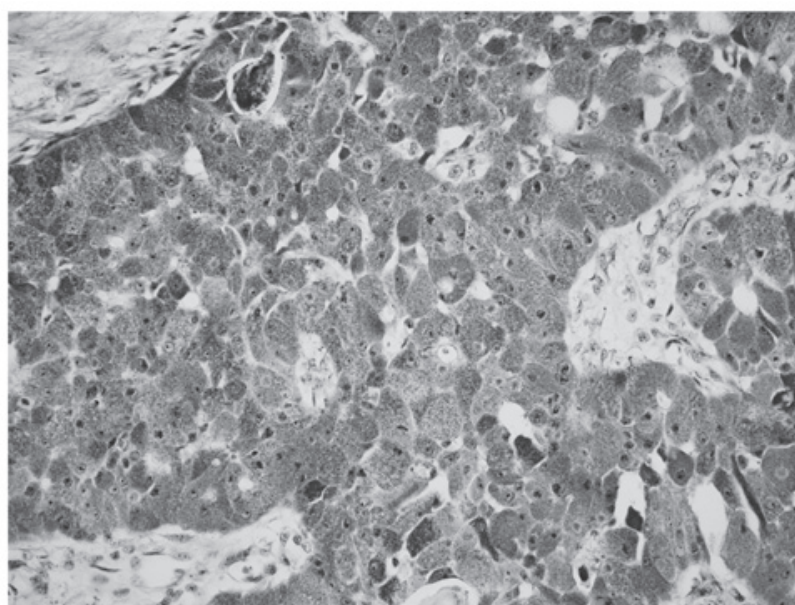

Figure 4. Mitochondria of the oncocytic carcinoma cells were stained (stain, phosphotungstic acid-hematoxylin; magnification, $\mathrm{x} 400$ ).

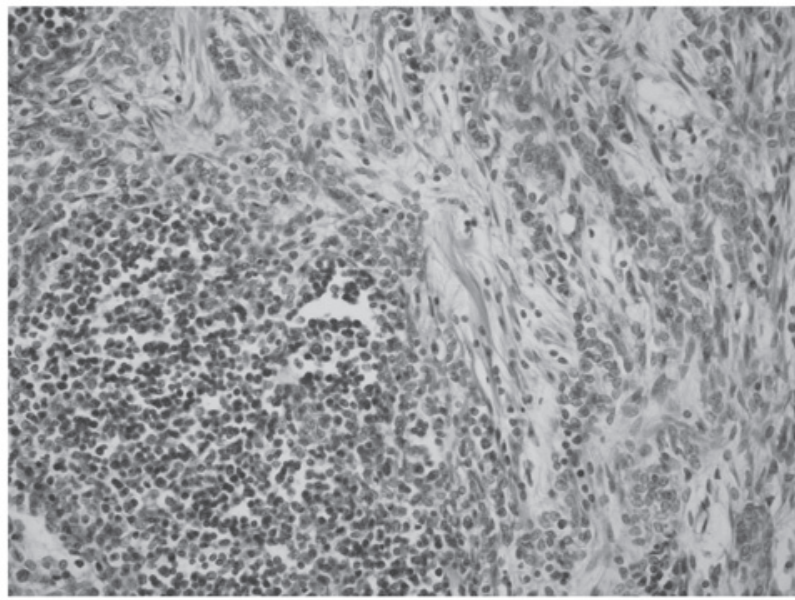

Figure 5. Thymoma, AB type, exhibiting type A with B-like features (stain, hematoxylin and eosin; magnification, x200).

Neoplastic elements were large, round or polyhedral cells and were arranged in solid sheets, islands and cords. The cytoplasm was abundant, eosinophilic and finely granular. The nuclei were large and centrally or peripherally located, and the nucleoli were distinct and large (Fig. 3). PTAH staining distinctly illustrated positive, small, dark-blue cytoplasmic granules, which represented mitochondria (Fig. 4). Tumor cells were positive for CK, CEA, S-100 and p53 by immunohistochemistry. Additionally, PTAH staining illustrated positive dark-blue cytoplasmic granules. The tumor of the thymus consisted of a homogeneous population of neoplastic epithelial cells that were spindle- or oval-shaped and lacked nuclear atypia, admixed with foci rich in lymphocytes. The segregation of the two patterns was sharp and distinct (Fig. 5).

\section{Discussion}

Oncocytes are large, granular, eosinophilic epithelial cells that are primarily found in glandular tissue, including that of the salivary glands and thyroid. In 1931, the pathologist Hamperl (26) used the term 'oncocyte' for this distinctive and typical cell type, which was taken from the Greek word 
Table I. Reports of oncocytic carcinomas in the salivary gland.

\begin{tabular}{|c|c|c|c|c|c|c|}
\hline Author (ref) & Age & Sex & Site & Size $(\mathrm{cm})$ & Rec. & LM \\
\hline Guclu (4) & 65 & $\mathrm{~F}$ & $\mathrm{P}$ & 3 & $\mathrm{Y}$ & $\mathrm{N}$ \\
\hline Mizutari (5) & 55 & M & $\mathrm{Sm}$ & 3 & $\mathrm{~N}$ & $\mathrm{~N}$ \\
\hline Kimura (6) & 61 & M & $\mathrm{P}$ & 4 & $\mathrm{~N}$ & $\mathrm{Y}$ \\
\hline Wischerath (7) & 59 & M & $\mathrm{Sm}$ & 2 & $\mathrm{~N}$ & $\mathrm{Y}$ \\
\hline Lombardi (8) & 45 & M & Oth & $\mathrm{N}$ & $\mathrm{N}$ & $\mathrm{N}$ \\
\hline Sugiyama (9) & 84 & M & Oth & 4 & $\mathrm{~N}$ & $\mathrm{~N}$ \\
\hline Ardekian (10) & 64 & M & $\mathrm{P}$ & 8 & $\mathrm{~N}$ & $\mathrm{~N}$ \\
\hline Cinar (11) & 48 & $\mathrm{~F}$ & $\mathrm{P}$ & 6 & $\mathrm{~N}$ & $\mathrm{Y}$ \\
\hline Muramatsu (12) & 82 & M & $\mathrm{Sm}$ & 4.5 & $\mathrm{~N}$ & $\mathrm{Y}$ \\
\hline Ozawa (13) & 58 & M & $\mathrm{P}$ & 3 & $\mathrm{~N}$ & $\mathrm{Y}$ \\
\hline Nakada (14) & 68 & M & $\mathrm{Sm}$ & 3 & $\mathrm{~N}$ & $\mathrm{Y}$ \\
\hline Corbridge (15) & 57 & M & $\mathrm{P}$ & 4 & $\mathrm{~N}$ & $\mathrm{Y}$ \\
\hline Yang (16) & 64 & M & $\mathrm{Sm}$ & 3.8 & $\mathrm{~N}$ & $\mathrm{Y}$ \\
\hline Wang (17) & 73 & M & $\mathrm{P}$ & 3 & $\mathrm{~N}$ & $\mathrm{Y}$ \\
\hline Tian (18) & 66 & M & $\mathrm{P}$ & 3 & $\mathrm{Y}$ & $\mathrm{N}$ \\
\hline Dong (19) & 57 & M & $\mathrm{Sm}$ & 3 & $\mathrm{~N}$ & N/A \\
\hline \multirow[t]{12}{*}{ Zhou (20) } & 60 & M & Oth & 3.5 & $\mathrm{Y}$ & $\mathrm{Y}$ \\
\hline & 57 & M & $\mathrm{P}$ & 7 & $\mathrm{~N}$ & $\mathrm{Y}$ \\
\hline & 48 & M & $\mathrm{P}$ & 3 & $\mathrm{~N}$ & $\mathrm{~N}$ \\
\hline & 59 & M & $\mathrm{P}$ & 8 & $\mathrm{~N}$ & $\mathrm{Y}$ \\
\hline & 75 & M & $\mathrm{P}$ & 3 & $\mathrm{Y}$ & $\mathrm{Y}$ \\
\hline & 68 & M & $\mathrm{P}$ & 4 & $\mathrm{Y}$ & $\mathrm{N}$ \\
\hline & 41 & M & $\mathrm{P}$ & 3 & $\mathrm{~N}$ & $\mathrm{~N}$ \\
\hline & 55 & M & $\mathrm{P}$ & 2.5 & $\mathrm{~N}$ & $\mathrm{Y}$ \\
\hline & 67 & $\mathrm{~F}$ & $\mathrm{P}$ & 3.5 & $\mathrm{Y}$ & $\mathrm{N}$ \\
\hline & 86 & M & $\mathrm{P}$ & 1 & $\mathrm{Y}$ & $\mathrm{N}$ \\
\hline & 51 & $\mathrm{~F}$ & Oth & 4 & $\mathrm{Y}$ & $\mathrm{Y}$ \\
\hline & 68 & M & $\mathrm{P}$ & 3 & $\mathrm{Y}$ & $\mathrm{N}$ \\
\hline Lee (21) & 51 & M & $\mathrm{Sm}$ & 3 & $\mathrm{~N}$ & $\mathrm{Y}$ \\
\hline Gallego (22) & 65 & M & $\mathrm{P}$ & 2.5 & $\mathrm{~N}$ & $\mathrm{Y}$ \\
\hline Present case & 66 & M & $\mathrm{P}$ & 2.5 & $\mathrm{~N}$ & $\mathrm{Y}$ \\
\hline
\end{tabular}

M, male; F, female; P, parotid; Sm, submaxillary salivary gland; Oth, other salivary gland; LM, lymph node metastasis; Rec., recurrence; N/A, not available; Y, yes; N, no.

'onkousthai' (27). Normal oncocytes are observed in the salivary glands of aged patients and are considered to represent an age-related metaplasia or degenerative process (28). In salivary gland ductal epithelium, the appearance of oncocytes (oncocytic metaplasia) is rare prior to the age of 50; however, it is nearly universal beyond age 70. In 1989, Linnane et al (29) hypothesized that aging is the accumulation of mtDNA errors that lead to mitochondrial 'respiratory failure' and multisystem degeneration.

According to the World Health Organization histologic classification of salivary gland tumors (30), parotid oncocytic neoplasms are divided into three categories, including oncocytosis, oncocytoma and OC. OC has been given several names in the past, including oncocytic adenocarcinoma, malignant oncycytoma and malignant oxyphilic adenoma. Sugimoto et al (31) reported that OC commonly presents as a parotid mass with pain and facial nerve paralysis, and that such symptoms were observed in one of three patients with OC. However, the primary symptom in the patient reported in the current study was a slowly progressive, painless mass. Oncocytic carcinomas appear to arise from benign oncocytomas; however, they may arise de novo (30). In the current case, the malignant nature of the neoplasm was evidenced by the regional and distant lymph node metastases. No perineural invasion or infiltration of subcutaneous tissue was observed. Criteria for the diagnosis of oncocytic carcinoma of the salivary gland include: i) distant metastasis; ii) local lymph node metastasis; iii) perineural, vascular, or lymphatic invasion; and iv) frequent mitoses and cellular pleomorphism with extensive invasion and destruction of adjacent structures (32).

It has been reported that $\mathrm{OC}$ occurs predominately in the parotid gland of older adults with a mean age of occurrence of 62.5 years, and two-thirds of all cases occurring in males (30). We reviewed previous literature from the past 15 years (Table I) and found only 32 cases of parotid OC. In the current case, the patient age (historically ranging from 41 to 86 years with a median age of 62.5 years) and tumor location (historically $62.5 \%$ in the parotid gland) were in agreement with those of the previous reports.

Oncocytic carcinoma can be differentiated from benign oncocytoma, since the former includes distant metastases; local lymph node metastases; perineural, intravascular, or lymphatic invasion; and mitoses and cellular polymorphisms with destructive invasion of adjacent structures. Ki-67 immunostaining has been proposed as a tool for distinguishing OC from oncocytomas (33). In a previous study, the frequency of Ki-67 positive cells with nuclear staining was higher in OC compared to oncocytomas (34).

In contrast to oncocytic carcinoma, salivary duct carcinoma forms duct-like spaces with papillary and cribriform growth, and displays comedonecrosis (2). In addition, the presence of numerous mitochondria in the cytoplasm of the oncocytes, as confirmed by ultrastructural examination, is not found in the neoplastic cells of the other malignancies mentioned above, which can also be used for adjuvant diagnosis. However, the processes of fixing or embedding the specimens for light microscopy often destroys the fine structure of organelles in the cytoplasm, making it difficult to observe mitochondria clearly.

Acinic cell adenocarcinoma may be differentiated from oncocytic carcinoma by its amphophilic or basophilic cytoplasmic granules, negative staining for mithochondrial antigens and the presence of a connective tissue capsule. Cytologic examination of Warthin's tumor shows oncocytes together with lymphocytes, amorphous material and cystic fluid. However, the possibility of oncocytoma should be considered when the smear contains only oncocytes (35).

PTAH staining has been successfully used to identify oncocytes; Brandwein and Huvos (36) particularly recommended the use of prolonged ( $48 \mathrm{~h}$ ) PTAH staining, which results in positive, dark-blue cytoplasmic granules. It has also been reported that immunohistochemistry using an anti-mitochondrial antibody is a highly sensitive and specific method for identifying mitochondria using light microscopy (37). 
Surgical excision is the most widely accepted method of treatment for OC (15), and the majority of the cases described in the literature have included neck dissection. Goode and Corio (38) reported that patients with tumors $<2 \mathrm{~cm}$ in diameter appeared to have a better prognosis than those that were larger. Adjuvant radiotherapy has been used for the treatment of oncocytic carcinoma, but its true contribution has not yet been elucidated. OC has a potential risk of distant metastasis, and lung, liver and brain metastases have been reported (32). The long-term survival of patients with OC is poor due to distant disease, and long-term follow-up is necessary after therapy (2). In the current study, the patient not only had OC but also thymoma, which is exceedingly rare and may represent the first documented case in the literature.

\section{Acknowledgements}

The authors thank Medjaden Bioscience Limited for assisting in the preparation of this manuscript.

\section{References}

1. Ellis GL, Auclair PL, Gnepp DR and Goode PK: Other malignant epithelial neoplasms. In: Surgical Pathology of the Salivary Glands. Ellis GL, Auclair PL, Gnepp DR (eds) Philadelphia, W. Saunders, pp455-488, 1991

2. Ellis GL and Auclair PL (eds): Tumors of the salivary glands In: Atlas of Tumor Pathology: Third Series, Fascicle 17. Armed Forces Institute of Pathology, Washington, DC, pp318-324, 1996.

3. Bauer WH and Bauer JD: Classification of glandular tumors of salivary glands; study of one-hundred forty-three cases. AMA Arch Pathol 55: 328-346, 1953.

4. Guclu E, Oghan F, Ozturk O, Alper M and Egeli E: A rare malignancy of the parotid gland: oncocytic carcinoma. Eur Arch Otorhinolaryngol 262: 567-569, 2005.

5. Mizutari K, Naganishi H and Tanaka Y: Oncocytic carcinoma in the submandibular gland: report of a case based on anti-mitochondrial immunohistochemical observations. Auris Nasus Larynx 32: 305-308, 2005.

6. Kimura M, Furuta T, Hashimoto S, Takano T and Nagao K: Oncocytic carcinoma of the parotid gland. A case report. Acta Cytol 47: 1099-1102, 2003.

7. Wischerath H, Brehmer D, Hesse G and Laubert A: Oncocytic adenocarcinoma of the submandibular gland. HNO 50: 565-569, 2002 (In German).

8. Lombardi D, Piccioni M, Farina D, Morassi ML and Nicolai P: Oncocytic carcinoma of the maxillary sinus: a rare neoplasm. Eur Arch Otorhinolaryngol 263: 528-531, 2006.

9. Sugiyama T, Nakagawa T, Narita M, Nakamura S, Inui M and Tagawa T: Pedunculated oncocytic carcinoma in buccal mucosa: immunohistochemical and ultrastructural studies. Oral Dis 12: 324-328, 2006

10. Ardekian L, Manor R, Peled M and Laufer D: Malignant oncocytoma of the parotid gland: case report and analysis of the literature. Oral Maxillofac Surg 57: 325-328, 1999.

11. Cinar U, Vural C, Basak T and Turgut S: Oncocytic carcinoma of the parotid gland: report of a new case. Ear Nose Throat J 82: 699-701, 2003

12. Muramatsu T, Hashimoto S, Lee MW, Chung CK, Matsuzaki K, Inoue T, Noma $\mathrm{H}$ and Shimono M: Oncocytic carcinoma arising in submandibular gland with immunohistochemical observations and review of the literature. Oral Oncol 39: 199-203,2003.

13. Ozawa H, Fujii M, Matsunaga T, Masuda K, Hirose S and Taiji H: Oncocytic carcinoma of the parotid gland. J Otolaryngol 35 189-192, 2006.

14. Nakada M, Nishizaki K, Akagi H, Masuda Y and Yoshino T: Oncocytic carcinoma of the submandibular gland: a case report and literature review. J Oral Pathol Med 27: 225-228, 1998.

15. Corbridge RJ, Gallimore AP, Dalton CG and O'Flynn PE: Oncocytomas of the upper jaw. Head Neck 18: 374-380, 1996.
16. Yang GZ, Gao LX and Ding HY: Salivary gland carcinoma with eosinophilia neuroendocrine differentiation. Chin J Pathol 33: 582-583, 2004.

17. Wang SY, Lou JL and DU XH: Oncocytic Carcinoma of Parotid Gland: A Case Report. J Oncol 14: 689-691, 2008.

18. Tian XQ and Wang WZ. Oncocytic carcinoma of Salivary gland, a case report. Zhong liu yan jiu yu lin chuang 14: 252-253, 2002

19. Dong DX, Shi PX and Li YL. Salivary Gland Cancer: A case report. J Diagn Pathol 8: 183-184, 2001.

20. Zhou CX, Shi DY, Ma DQ, Zhang JG, Yu GY and Gao Y: Primary oncocytic carcinoma of the salivary glands: A clinicopathologic and immunohistochemical study of 12 cases. Oral Oncol 46: 773-778, 2010.

21. Lee WY and Chang SL: Fine needle aspiration cytology of oncocytic carcinoma of the submandibular gland with pre-existing oncocytoma: a case report. J Cytopathology 21: 339-341, 2010.

22. Gallego L, García-Consuegra L, Fuente E, Calvo N and Junquera L: Oncocytic carcinoma of the parotid gland with late cervical lymph node metastases: a case report. J Med Case Rep 5: 11, 2011.

23. Fornasiero A, Daniele O, Ghiotto C, et al: Chemotherapy of invasive thymoma. J Clin Oncol 8: 1419-1423, 1990.

24. Detterbeck FC and Parsons AM: Thymic tumors. Ann Thorac Surg 77: 1860-1869, 2004

25. Marx A, Harris NL, Strobel Ph, et al: Thymomas. In: World Health Organization Classification of Tumours. Pathology and Genetics of Tumours of the Lung, Pleura, Thymus and Heart. Travis DW, Brambilla E, Muller-Hermelink HK and Harris CC (eds): IARC Press: Lyon, pp152-157, 2004.

26. Hamperl H: Beitrage zur normalen und pathologischen histology menschlicher speicheldrusen. Z Microanat Forsch 27: 1-55, 1931 (In German).

27. Alberty J, August C and Stoll W: Oncocytic neoplasms of the parotid gland. Differential diagnosis, clinical course and review of the literature. HNO 49: 109-117, 2001 (In German).

28. Dardick I, Birek C, Lingen MW and Rowe PE: Differentiation and the cytomorphology of salivary gland tumors with specific reference to oncocytic metaplasia. Oral Surg Oral Med Oral Pathol Oral Radiol Endod 88: 691-701, 1999.

29. Linnane AW1, Marzuki S, Ozawa T and Tanaka M: Mitochondrial DNA mutations as an important contributor to ageing and degenerative diseases. Lancet 25: 642-645, 1989.

30. Sciubba JJ and Shimono M: Oncocytic carcinoma. In: World Health Organization Classification of Tumors: Pathology and Genetics: Head and Neck Tumours. Barnes L, Eveson JW, Reichart D and Sidransky D (eds). IARC Press, Lyon, pp235, 2005.

31. Sugimoto T, Wakizono S, Uemura T, Tsuneyoshi $M$ and Enjoji M: Malignant oncocytoma of the parotid gland: a case report with an immunohistochemical and ultrastructural study. J Laryngol Otol 107: 69-74, 1993.

32. Gray SR, Cornog JL Jr and Seo IS: Oncocytic neoplasms of salivary glands: a report of fifteen cases including two malignant oncocytomas. Cancer 38: 1306-1317, 1976.

33. Ito K, Tsukuda M, Kawabe R, et al: Benign and malignant oncocytoma of the salivary glands with an immunohistochemical evaluation of Ki-67. ORL J Otorhinolaryngol Relat Spec 62: 338-341, 2000.

34. Zhou CX and Gao Y: Oncocytoma of the salivary glands: a clinicopathologic and immunohistochemical study. Oral Oncol 45: e232-e238, 2009.

35. Yang $\mathrm{T}$ and Guo LN: Oncocytic carcinoma. In: Diagnostic Pathology: First Series. Liu TH (ed). People's Medical Publishing Press, Beijing, pp617-618, 2013.

36. Brandwein MS and Huvos AG: Oncocytic tumors of major salivary glands: a study of 68 cases with follow-up of 44 patients. Am J Surg Pathol 15: 514-528, 1991.

37. Shintaku M and Honda T: Identification of oncocytic lesions of salivary glands by anti-mitochondrial immunohistochemistry. Histopathology 31: 408-411, 1997.

38. Goode RK and Corio RL: Oncocytic adenocarcinoma of salivary glands. Oral Surg Oral Med Oral Pathol 65: 61-66, 1988. 